Article

\title{
Biomechanical Analyses of Porous Designs of 3D-Printed Titanium Implant for Mandibular Segmental Osteotomy Defects
}

\author{
Yen-Wen Shen ${ }^{1,+}{ }^{,}$Yuen-Shan Tsai ${ }^{1,+}$, Jui-Ting Hsu ${ }^{1,2} \oplus$, Ming-You Shie ${ }^{1,2,3} \oplus$, Heng-Li Huang ${ }^{1,2, * \mathbb{C}}$ \\ and Lih-Jyh Fuh $1, * \mathbb{B}$
}

1 School of Dentistry, China Medical University, Taichung 404, Taiwan; a2312830@ms28.hinet.net (Y.-W.S.); sunshine120807@gmail.com (Y.-S.T.); jthsu@mail.cmu.edu.tw (J.-T.H.); eric@mail.cmu.edu.tw (M.-Y.S.)

2 Department of Bioinformatics and Medical Engineering, Asia University, Taichung 413, Taiwan

3 x-Dimension Center for Medical Research and Translation, China Medical University Hospital, Taichung 404, Taiwan

* Correspondence: henleyh@gmail.com (H.-L.H.); ljfuh@mail.cmu.edu.tw (L.-J.F.); Tel.: +886-4-2205-3366 (ext. 2306) (H.-L.H.); +886-4-2205-3366 (ext. 2312) (L.-J.F.); Fax: +886-4-2201-4043 (H.-L.H.)

+ These authors contributed equally to this work.

Citation: Shen, Y.-W.; Tsai, Y.-S.; Hsu J.-T.; Shie, M.-Y.; Huang, H.-L.; Fuh, L.-J. Biomechanical Analyses of Porous Designs of 3D-Printed Titanium Implant for Mandibular Segmental Osteotomy Defects. Materials 2022, 15, 576. https:// doi.org/10.3390/ma15020576

Academic Editor: Alessandro Pistone

Received: 23 November 2021

Accepted: 11 January 2022

Published: 13 January 2022

Publisher's Note: MDPI stays neutral with regard to jurisdictional claims in published maps and institutional affiliations.

Copyright: (C) 2022 by the authors. Licensee MDPI, Basel, Switzerland. This article is an open access article distributed under the terms and conditions of the Creative Commons Attribution (CC BY) license (https:// creativecommons.org/licenses/by/ $4.0 /)$

\begin{abstract}
Clinically, a reconstruction plate can be used for the facial repair of patients with mandibular segmental defects, but it cannot restore their chewing function. The main purpose of this research is to design a new three-dimensionally (3D) printed porous titanium mandibular implant with both facial restoration and oral chewing function reconstruction. Its biomechanical properties were examined using both finite element analysis (FEA) and in vitro experiments. Cone beam computed tomography images of the mandible of a patient with oral cancer were selected as a reference to create 3D computational models of the bone and of the 3D-printed porous implant. The pores of the porous implant were circles or hexagons of 1 or $2 \mathrm{~mm}$ in size. A nonporous implant was fabricated as a control model. For the FEA, two chewing modes, namely right unilateral molar clench and right group function, were set as loading conditions. Regarding the boundary condition, the displacement of both condyles was fixed in all directions. For the in vitro experiments, an occlusal force (100 N) was applied to the abutment of the 3D-printed mandibular implants with and without porous designs as the loading condition. The porous mandibular implants withstood higher stress and strain than the nonporous mandibular implant, but all stress values were lower than the yield strength of Ti-6Al-4V (800 MPa). The strain value of the bone surrounding the mandibular implant was affected not only by the shape and size of the pores but also by the chewing mode. According to Frost's mechanostat theory of bone, higher bone strain under the porous implants might help maintain or improve bone quality and bone strength. The findings of this study serve as a biomechanical reference for the design of 3D-printed titanium mandibular implants and require confirmation through clinical investigations.
\end{abstract}

Keywords: mandibular segmental defect; 3D-printed porous titanium mandibular implant; pore shape; pore size; finite element analysis; strain gauge in vitro experiment; stress; strain

\section{Introduction}

Mandibular segmental defects typically result from jaw trauma, tumor resection, or osteoradionecrosis. If not treated early, they can compromise patients' ability to talk and eat. Common clinical treatments for segmental defects of the mandible include autologous bone grafting and bone plate reconstruction. Autologous bone grafting typically involves one of two types of implants, nonvascularized bone grafts and vascularized bone flaps, which commonly use the fibula, ilium, or ribs as donor sites [1,2]. Patients indicated for such procedures typically undergo a preoperative evaluation through which factors such as age and the location and severity of the defect are considered [3]. The defect severity can be clinically used to determine the method of transplantation. If the area of a segmental 
mandibular defect is small, a nonvascularized bone flap graft or a bone plate is employed. If the area is large, vascularized bone flap transplantation is preferred [4,5]. However, patients with large-scale bone defects may still cause possible peri-implant bone loss [6,7], even if they received the treatment of bone grafting mentioned above and dental implant.

With advances in medical image processing, computed tomography (CT) and magnetic resonance imaging have become more precise and can even reach the micro-level to analyze material structure and new bone formation processes [8]. With the aid of software, the internal structure of the human body can now be displayed as three-dimensional (3D) images, assisting physicians in making more accurate presurgical evaluations. These images can be directly read by 3D printers after they have been converted into the Surface Tessellation Language file format; thus, the popularity of 3D printing technology in medicine is growing [9-11].

The use of 3D printing technology to make a solid model of a patient's bones as an aid in preoperative and postoperative assessment is increasing. Employing 3D printing technology in this context can reduce both the time and cost of the operation $[10,12,13]$. Notably, patient-specific 3D-printed implants have passed the in vitro and animal testing phases and have entered clinical settings [14,15]. For example, 3D printing has been used in recent years in craniofacial and maxillofacial surgery to fabricate patient-specific Ti cranial or oral implants [16-18].

The inspiration for this research was a study by Huang et al. (2018) [19]. Finite element analysis (FEA) of their self-designed metal mandibular implants for segmental mandibular defects revealed that, regardless of changes in the shape, thickness, or length of the implants, high stress occurred at specific locations. These included the position of the base post close to the abutment as well as the wing plate used to connect the implant to the mandible. The purpose of this study is to optimize the biomechanical performance of 3D-printed metal mandibular implants with prosthetic bases for segmental mandibular defects wherein the design parameters of circular and hexagonal pores were applied. FEA and in vitro experiments were conducted to investigate how the porous structure affected the stress-strain distributions of the implant body and of the surrounding bone.

\section{Materials and Methods}

\subsection{D Computer Model Establishment}

The study protocol was approved by the Institutional Review Board (IRB) of China Medical University Hospital (approval no. CMUH108-REC3-174). Specifically, permission was granted for the acquisition of cone beam CT images of the mandible of a patient with oral cancer (Planmeca ProMax 3D Max, Planmeca USA, Hoffman Estates, IL, USA). The voxel resolution of the images was $0.65 \mathrm{~mm}$. The images were imported into the medical image processing software Mimics (Materialise, Leuven, Belgium) to identify the contours of cortical bone and spongy bone through the separation of grayscale threshold values. Subsequently, these contours were saved in the Initial Graphics Exchange Specification file format and imported into a reverse engineering software (Geomagic Inc., Morrisville, NC, USA) to establish a primary model of mandibular reconstruction. After the uneven surface of the model was smoothed, the model was imported into a computer-aided design software (Solidworks, Dassault Systemes SE, France), with the $x$-axis corresponding to the tongue and the buccal direction, the $y$-axis corresponding to the mesial and distal direction, and the $z$-axis corresponding to the bite direction.

After the right malignant tumor bone from the patient's 3D mandibular model was removed programmatically, the main body and wing plate of the mandibular implant were designed according to the characteristics of the defect site (Figure 1). First, the implant conformed to the anatomical shape of the mandible, and the main part of the implant was hollow and $0.5 \mathrm{~mm}$ thick. The hollow body provides space for bone growth under bone grafting. Second, round and hexagonal pores with diameters of 1 and $2 \mathrm{~mm}$ were used. The porous design was intended to increase blood flow both inside and outside the implant, thereby promoting healing after bone grafting. Furthermore, it reduced the weight of the 
implant [20]. The abutment base was situated $3 \mathrm{~mm}$ above the implant. The abutment base can be connected to the crown to restore the patient's occlusal function (Figure 1).

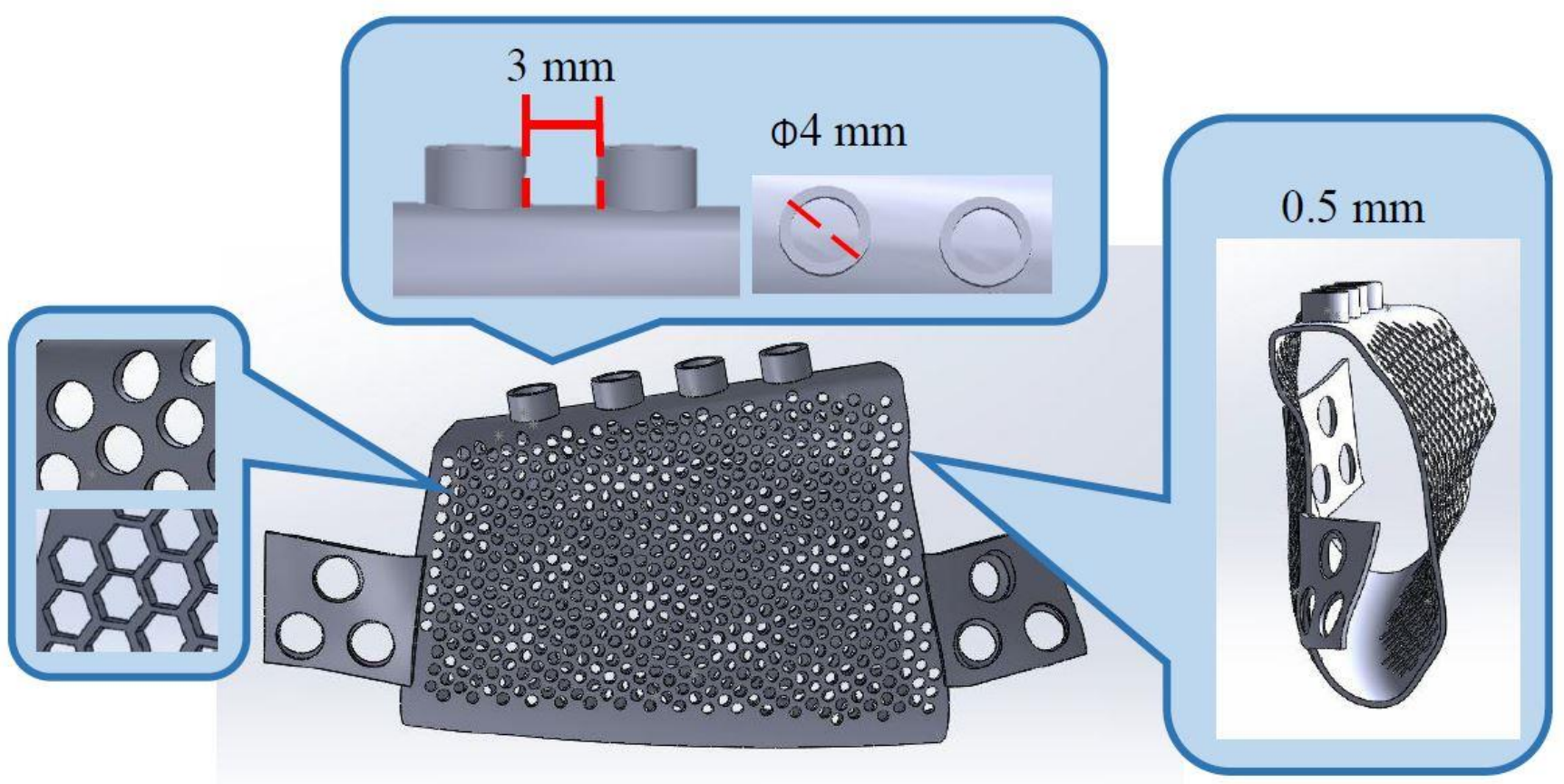

Figure 1. Design features of the metal mandibular implant.

Two wing plates were set on both sides of the implant. Each wing plate had three screw holes to secure the plate to the mandible, and the implant can be positioned at the mandibular resection. To achieve a satisfactory fit between the jawbone surface and each wing plate, a model of the curved surface of the jawbone was imported into the Rhinoceros 4 software (Robert McNeel \& Associates, Seattle, WA, USA).

Five mandibular implant models (Figure 2) were designed. The control model had no pores. As for the other four models, they featured round holes $2 \mathrm{~mm}$ in diameter, round holes $1 \mathrm{~mm}$ in diameter, hexagonal holes $2 \mathrm{~mm}$ in diameter, and hexagonal holes $1 \mathrm{~mm}$ in diameter. After the five models were combined with the model of the mandible, a finite element analysis was performed.

\subsection{FEA}

After the five 3D models were imported into the Ansys software (version 2020 R2; Ansys, Inc., Canonsburg, PA, USA), the second-order tetrahedral elements were used for meshing to create a 3D model for FEA.

The material parameters are presented in Table 1 [19]. Settings of linear elastic, isotropic, and homogeneous materials were applied to the cortical bone, cancellous bone, mandibular implants, and screws. The displacements of the condyles in the $x, y$, and $z$ directions were fixed at zero. The bone-screw interface was bonded, as was the bone plate-screw interface.

Two occlusal modes were employed for load simulation. Specifically, the three primary muscles used in mandibular movement, namely the masseter, medial pterygoid, and temporalis, were set to the right unilateral molar clench (RMOL) and right group function (RGF) modes (Figure 3) [21,22]. The loading conditions are presented in Table 2. 


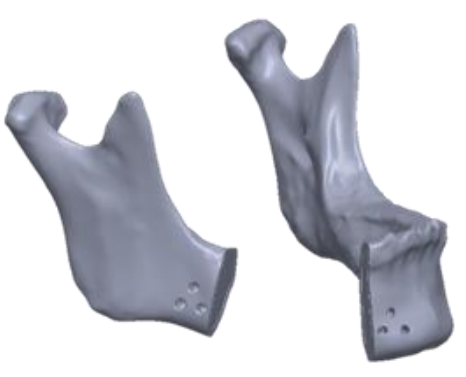

(a)

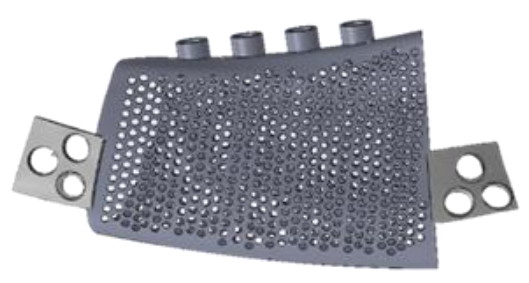

(d)

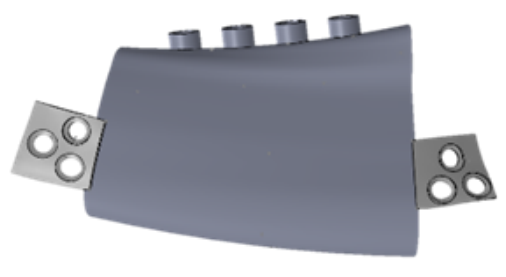

(b)

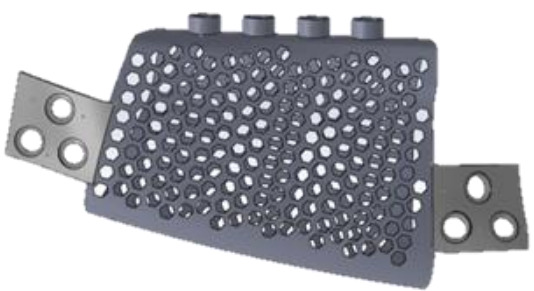

(e)

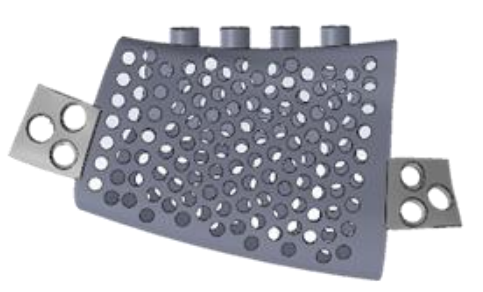

(c)

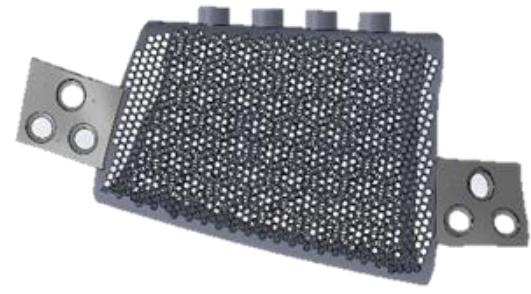

(f)

Figure 2. (a) Mandibular model and metal mandibular implants (b) without pores, (c) with circular holes $2 \mathrm{~mm}$ in diameter, (d) with circular holes $1 \mathrm{~mm}$ in diameter, (e) with hexagonal holes $2 \mathrm{~mm}$ in diameter, and (f) with hexagonal holes $1 \mathrm{~mm}$ in diameter.

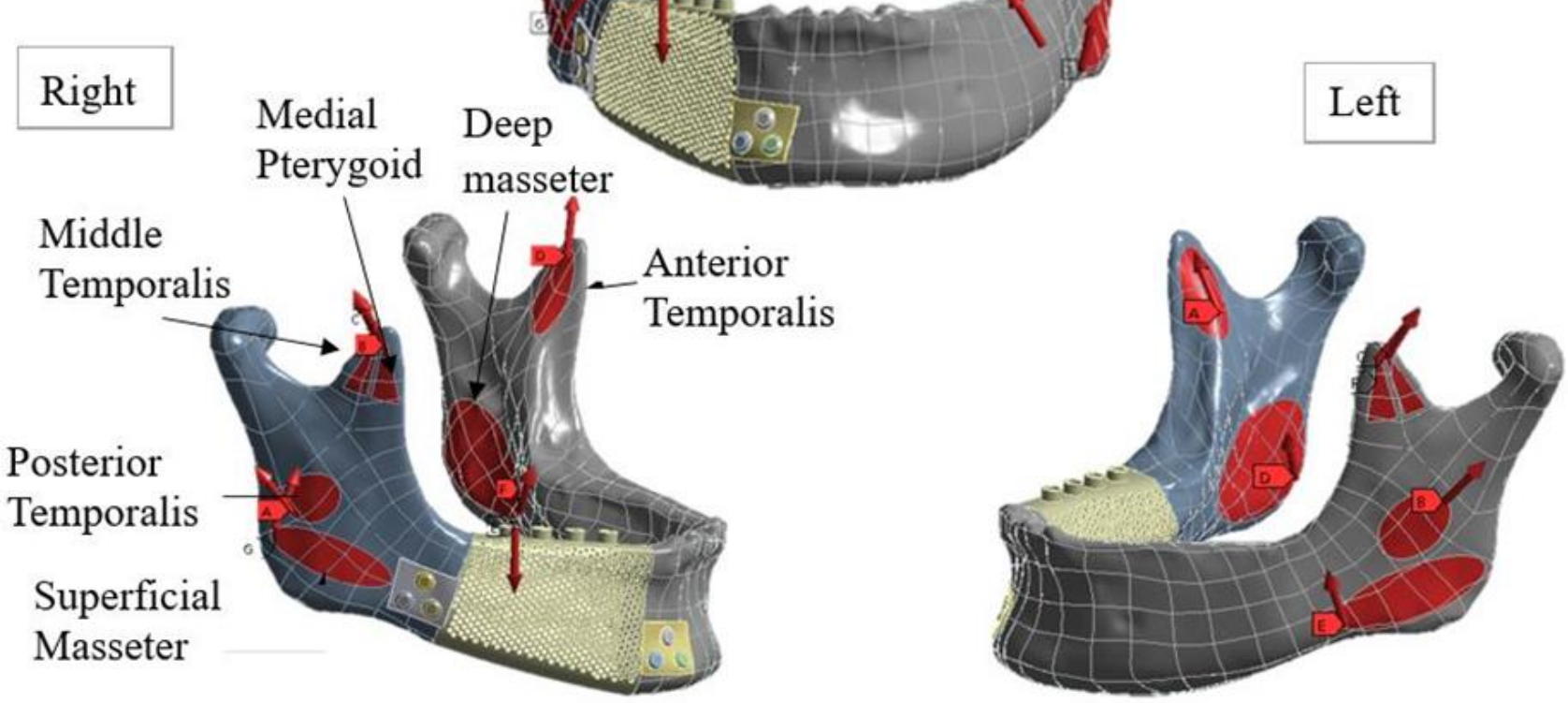

Figure 3. Loading conditions. 
Table 1. Material parameters of the model [19].

\begin{tabular}{ccc}
\hline Material & $\begin{array}{c}\text { Young's Modulus } \\
(\mathbf{M P a})\end{array}$ & Poisson's Ratio \\
\hline 3D-printed titanium alloy & 129,000 & 0.34 \\
Titanium alloy & 110,000 & 0.33 \\
Cortical bone & 13,400 & 0.3 \\
Trabecular bone & 790 & 0.3 \\
\hline
\end{tabular}

Table 2. Magnitude of each muscular force under the RMOL and RFG loading conditions [21,22].

\begin{tabular}{|c|c|c|c|c|c|c|c|c|c|}
\hline \multirow{2}{*}{$\begin{array}{l}\text { Clenching } \\
\text { Tasks }\end{array}$} & \multirow{2}{*}{ Side } & \multirow{2}{*}{ Direction } & \multicolumn{6}{|c|}{ Muscular Force } & \multirow{2}{*}{ Occlusal Force } \\
\hline & & & SM & DM & MP & AT & MT & PT & \\
\hline \multirow{8}{*}{ RMOL } & \multirow{4}{*}{ Right } & Force & 137.1 & 58.8 & 146.8 & 115.3 & 63.1 & 44.6 & \multirow{8}{*}{$\begin{array}{l}\mathrm{Fx} \\
\mathrm{Fy} \\
\mathrm{Fz}\end{array}$} \\
\hline & & $\mathrm{Fx}$ & -28.1 & -32.1 & 71.4 & -17.2 & -14.0 & -9.3 & \\
\hline & & Fy & -57.4 & 21.0 & -54.8 & -5.1 & 31.5 & 38.1 & \\
\hline & & $\mathrm{Fz}$ & 121.2 & 44.5 & 116.1 & 114.0 & 52.8 & 21.1 & \\
\hline & \multirow{4}{*}{ Left } & Force & 114.2 & 49.0 & 104.9 & 91.6 & 64.1 & 29.5 & \\
\hline & & $\mathrm{Fx}$ & 23.6 & 26.7 & -51.0 & 13.7 & 14.2 & 6.1 & \\
\hline & & Fy & -47.9 & 17.5 & -39.1 & -4.0 & 32.0 & 25.2 & \\
\hline & & $\mathrm{Fz}$ & 101.0 & 37.1 & 83.0 & 90.5 & 53.6 & 14.0 & \\
\hline \multirow{8}{*}{ RGF } & \multirow{4}{*}{ Right } & Force & 34.3 & 29.4 & 12.2 & 104.3 & 61.2 & 46.9 & \multirow{8}{*}{$\begin{array}{l}\mathrm{Fx} \\
\mathrm{Fy} \\
\mathrm{Fz}\end{array}$} \\
\hline & & $\mathrm{Fx}$ & -7.1 & -16.0 & 6.0 & -15.5 & -13.6 & 9.8 & \\
\hline & & Fy & -14.4 & 10.5 & -4.6 & -4.6 & 30.6 & 40.1 & \\
\hline & & $\mathrm{Fz}$ & 30.3 & 22.3 & 9.7 & 103.0 & 51.2 & 22.2 & \\
\hline & \multirow{4}{*}{ Left } & Force & 51.4 & 21.2 & 132.8 & 11.1 & 5.7 & 4.5 & \\
\hline & & $\mathrm{Fx}$ & 10.6 & 11.6 & $\begin{array}{l}132.0 \\
-64.6\end{array}$ & $\begin{array}{c}11.1 \\
1.7\end{array}$ & $\begin{array}{c}0.7 \\
-1.3\end{array}$ & $\begin{array}{c}4.5 \\
-0.9\end{array}$ & \\
\hline & & Fy & -21.5 & 7.6 & -49.6 & -0.5 & 2.9 & 3.9 & \\
\hline & & $\mathrm{Fz}$ & 45.4 & 16.1 & 105.1 & 10.9 & 4.8 & 2.2 & \\
\hline
\end{tabular}

Note: SM, DM, MP, AT, MT, and PT refer to the superficial masseter, deep masseter, medial pterygoid, anterior temporalis, middle temporalis, and posterior temporalis, respectively. The occlusal forces were applied on the molar and premolar areas under the RMOL and RFG modes, respectively.

\subsection{D Printing and In Vitro Experiments}

To evaluate the effects of the porous design on the biomechanical performance of the titanium mandibular implant, experiments were conducted on the control implant and on the implant with $1 \mathrm{~mm}$ circular holes. The Objet 500 Connex3, a light-curing 3D printer (Stratasys, Eden Prairie, MN, USA), was employed. In order to increase the anatomical accuracy of the mandibular bone model in this experiment, two types of resin with differing densities, specifically VeroWhitePlus (Stratasys) and TangoPlus (Stratasys), were used to fabricate the compact and cancellous bone of the mandibular bone model, respectively.

The metal mandibular implant was constructed using the Renishaw AM400 SLM 3D printer (Renishaw plc, Wotton-under-Edge, Gloucestershire, UK). The implant material was a TiAlV alloy. Following 3D printing, the implant model was placed in the resin model of the mandible, and $2.7 \times 12 \mathrm{~mm}$ screws (50-27412, Stryker, Kalamazoo, MI, USA) were locked into the wing plate to construct a model of the implant (Figure 4).

As displayed in Figure 5b, strain gauge rosettes (Kyowa Electronic Instruments Co., Ltd., Tokyo, Japan) comprising three independent strain gauges $(\varepsilon a, \varepsilon b$, and $\varepsilon c)$ were adhered to the implant body (designated as position $\mathrm{A}$ ) and the surrounding bone (designated as positions $B$ and $C$ ). The strain values at three locations were determined using a data acquisition system (CompactDAQ, National Instruments, Austin, TX, USA) and the associated software (LabVIEW SignalExpress 3.0, National Instruments, Austin, TX, USA). 


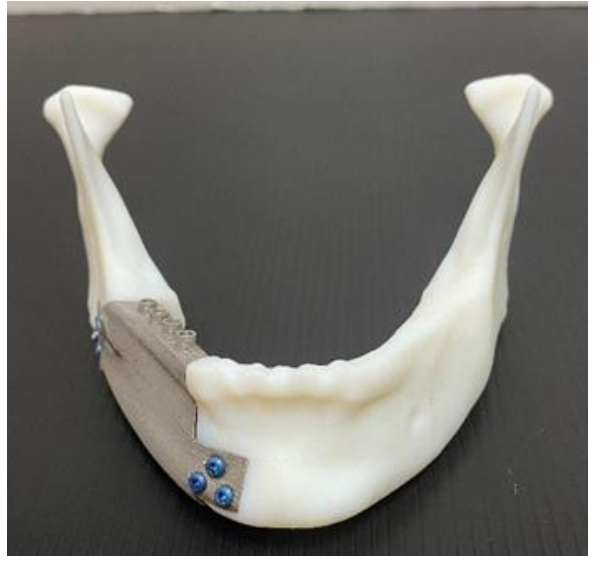

(a)

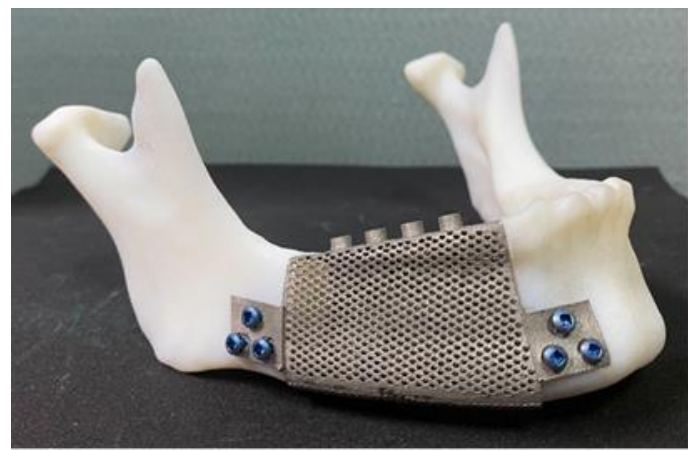

(b)

Figure 4. (a) Frontal view of the control sample; (b) lateral view of the experimental sample.

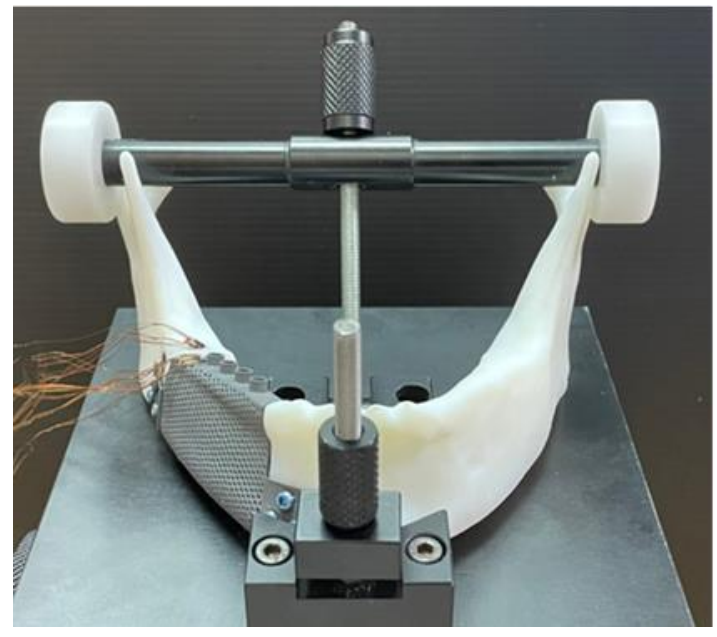

(a)

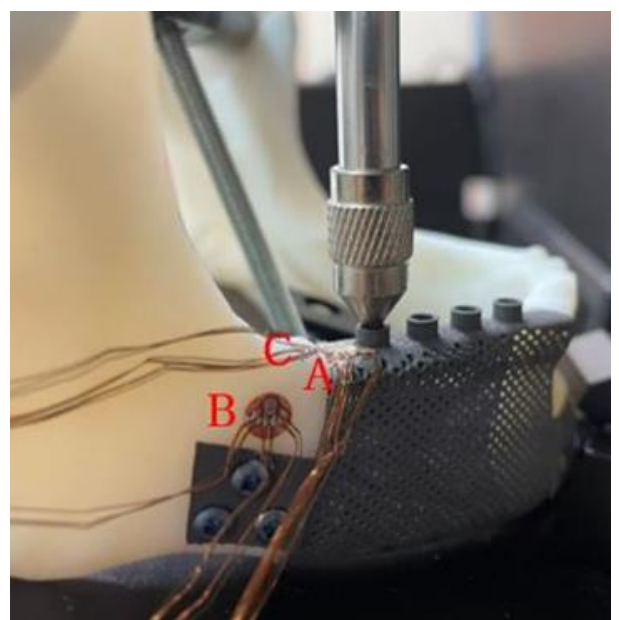

(b)

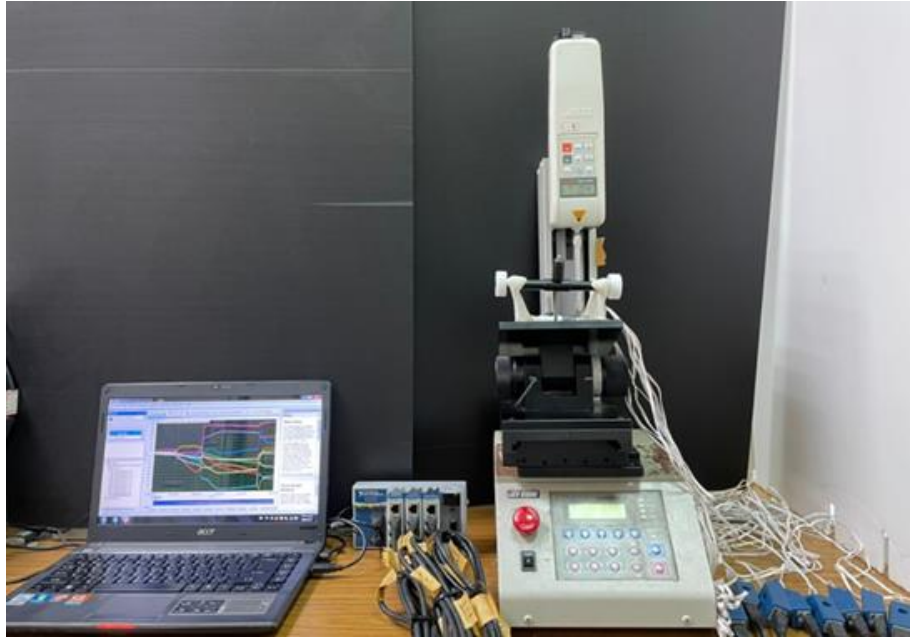

(c)

Figure 5. Photographs of (a) the experimental sample on the self-developed jig; (b) the positions of the strain gauge rosettes and their corresponding loading conditions (A indicates the implant body; B and $\mathrm{C}$ indicate the surrounding bone); and (c) equipment used for the in vitro experiments. 
The regions between the condylar and coronoid processes as well as the mental protuberance of the full jawbone model were fixed by installing a self-developed jig (Figure 5a) on the testing platform of a loading machine (JSV-H1000, Japan Instrumentation System, Nara, Japan). Regarding the loading conditions, the loading head axially pressed down on the abutment base of the right mandible at a speed of $1 \mathrm{~mm}$ per minute (Figure $5 \mathrm{~b}$ ). After each measurement had been repeated five times for each sample, the maximum ( $\varepsilon$ max) and minimum ( $\varepsilon \mathrm{min}$ ) principal strains of $\varepsilon a, \varepsilon b$, and $\varepsilon c$ were determined (Figure $5 c$ ).

All the measured data are presented as medians and interquartile ranges because of the small sample size. The Wilcoxon rank sum test was performed to compare the measurement data corresponding to the porous and nonporous implant designs. Analyses were conducted using SPSS version 19 (IBM, Armonk, NY, USA). The alpha value was 0.05.

\section{Results}

\subsection{In Vitro Experiments}

The results of analyses of the maximum principal strain (tensile strain) and the minimum principal strain (compressive strain) of the control sample and the sample with $1 \mathrm{~mm}$ circular holes are presented in Table 3.

Table 3. Maximum and minimum principal strains of the control and experimental samples.

\begin{tabular}{|c|c|c|c|c|c|}
\hline & Position & & Control & Experiment & $p$ \\
\hline \multirow{6}{*}{$\begin{array}{c}\text { Max } \\
\text { principal } \\
\text { strain } \\
(\mu \text { strain })\end{array}$} & \multirow{2}{*}{ A } & Median & 715.23 & -90.61 & \multirow[b]{2}{*}{0.021} \\
\hline & & IQR & 221.00 & 738.48 & \\
\hline & \multirow{2}{*}{ B } & Median & 1270.42 & 3114.37 & \multirow{2}{*}{0.021} \\
\hline & & IQR & 260.84 & 419.94 & \\
\hline & \multirow[b]{2}{*}{$\mathrm{C}$} & Median & 480.41 & 1109.03 & \multirow[b]{2}{*}{0.021} \\
\hline & & IQR & 89.44 & 2442.460 & \\
\hline \multirow{5}{*}{$\begin{array}{c}\text { Min principal } \\
\text { strain } \\
\text { ( } \mu \text { strain })\end{array}$} & A & Median & -1525.53 & -2246.89 & 0.021 \\
\hline & \multirow[b]{2}{*}{ B } & $\begin{array}{l}\text { MQR } \\
\text { Median }\end{array}$ & $\begin{array}{c}218.18 \\
-124042\end{array}$ & $\begin{array}{c}96.52 \\
-107721\end{array}$ & \multirow[b]{2}{*}{0.083} \\
\hline & & IQR & 174.62 & 184.85 & \\
\hline & \multirow{2}{*}{$\mathrm{C}$} & Median & -1497.91 & -514.52 & \multirow{2}{*}{0.021} \\
\hline & & IQR & 148.19 & 461.84 & \\
\hline
\end{tabular}

Note: IQR refers to interquartile range.

As presented in Table 3 the control and experimental samples differed significantly $(p<0.05)$ in the maximum principal strain at positions A, B, and C. A significant betweensample difference was also observed between the minimum principal strain at positions $A$ and $C(p<0.05)$. However, no significant difference in the minimum principal strain at location B was noted $(p>0.05)$.

\subsection{FEA}

The results of the convergence analysis are shown in Figure 6. In line with expectations, a $0.4 \mathrm{~mm}$ element size for the implant and the surrounding bone mesh resulted in an error of $0.56 \%$ in the convergence results of the implant body.

\subsubsection{Von Mises Stress of the Implant Body}

RMOL mode. The peak stress of the control sample, $162.31 \mathrm{MPa}$, occurred around the base of abutments near the first and second molar areas (Figure 7). The peak stresses of the implants with $2 \mathrm{~mm}$ and $1 \mathrm{~mm}$ circular holes were 215 and $271 \mathrm{MPa}$, respectively, and the peak stresses of the implants with $2 \mathrm{~mm}$ and $1 \mathrm{~mm}$ hexagonal holes were 255 and $299 \mathrm{MPa}$, respectively. For mandibles with both circular and hexagonal holes, high stress was detected not only around the base of the abutments but also near the holes close to the base of the abutment (Figure 7). 


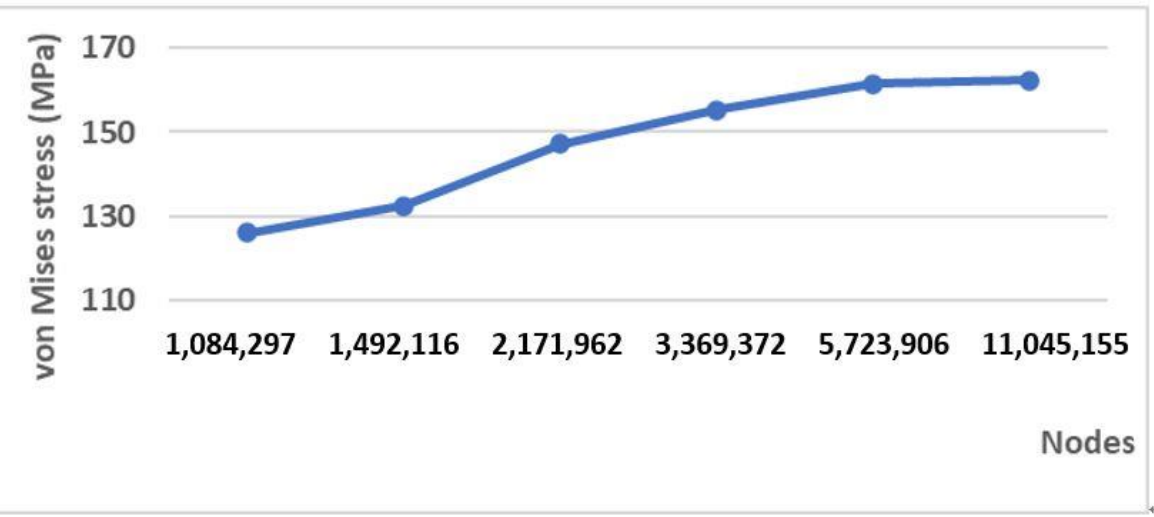

Figure 6. Results of the convergence test.

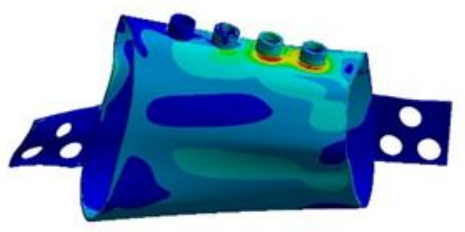

(a)

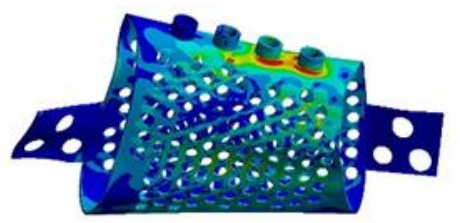

(b)

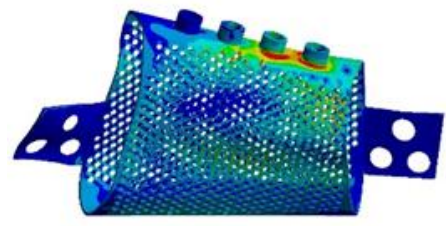

(c)

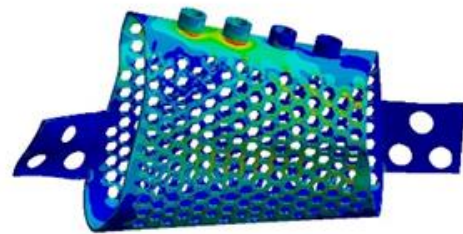

(d)

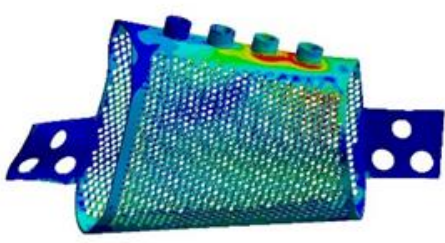

(e)

Figure 7. Von Mises stress distributions of the models in RMOL mode (a) without pores, (b) with circular holes $2 \mathrm{~mm}$ in diameter, (c) with circular holes $1 \mathrm{~mm}$ in diameter, (d) with hexagonal holes $2 \mathrm{~mm}$ in diameter, and (e) with hexagonal holes $1 \mathrm{~mm}$ in diameter.

RGF mode. The peak stress of the control sample was $112.66 \mathrm{MPa}$. The peak stresses of the implants with $2 \mathrm{~mm}$ circular holes, $1 \mathrm{~mm}$ circular holes, $2 \mathrm{~mm}$ hexagonal holes, and $1 \mathrm{~mm}$ hexagonal holes were 141,188, 247, and $332 \mathrm{MPa}$, respectively. The high-stress areas under the RMOL and RGF modes were similar (Figure 8).

\subsubsection{Von Mises Strain in the Bone around the Implant}

RMOL mode. The maximum von Mises strain in the bone around the control implant was $2664 \mu \varepsilon$. The maximum von Mises strains in the bone around the implants with $2 \mathrm{~mm}$ and $1 \mathrm{~mm}$ circular holes were 2648 and $2744 \mu \varepsilon$, respectively. The corresponding values for the implants with $2 \mathrm{~mm}$ and $1 \mathrm{~mm}$ hexagonal holes were 2678 and $2813 \mu \varepsilon$, respectively. High bone strain was observed near the connection area between the lingual side of the jawbone and the implant (Figure 9).

RGF mode. The maximum von Mises strain in the bone around the control implant was $1283 \mu \varepsilon$. The corresponding values for the implants with $2 \mathrm{~mm}$ circular holes, $1 \mathrm{~mm}$ circular holes, $2 \mathrm{~mm}$ hexagonal holes, and $1 \mathrm{~mm}$ hexagonal holes were 1250, 1161, 1354, and $1493 \mu \varepsilon$, respectively. The high-strain distributions of bone under the RMOL and RGF modes were similar (Figure 10). 


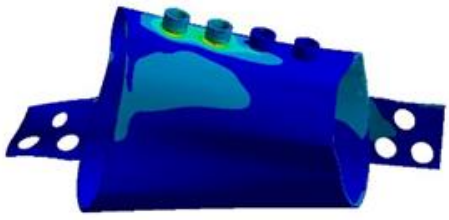

(a)

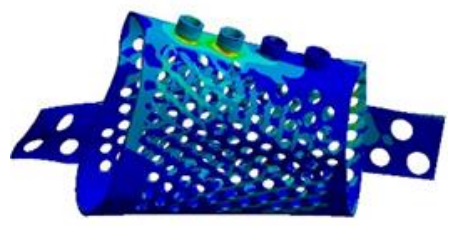

(b)

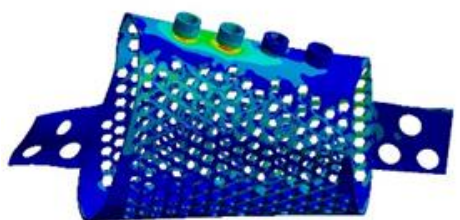

(d)

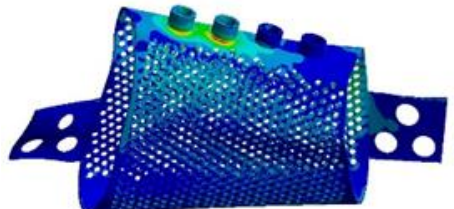

(c)

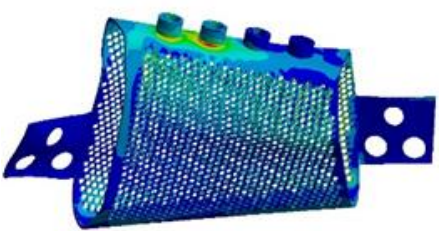

(e)

Figure 8. Von Mises stress distributions of the models in RGF mode (a) without pores, (b) with circular holes $2 \mathrm{~mm}$ in diameter, (c) with circular holes $1 \mathrm{~mm}$ in diameter, (d) with hexagonal holes 2 $\mathrm{mm}$ in diameter, and (e) with hexagonal holes $1 \mathrm{~mm}$ in diameter.

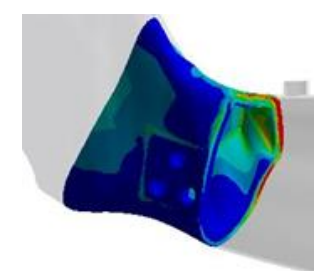

(a)

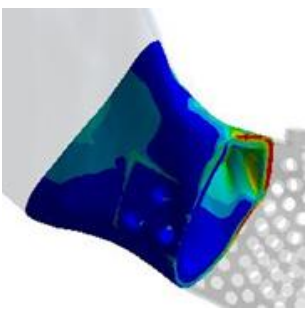

(b)

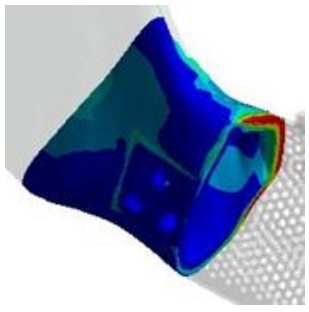

(c)

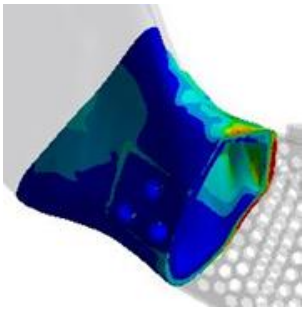

(d)

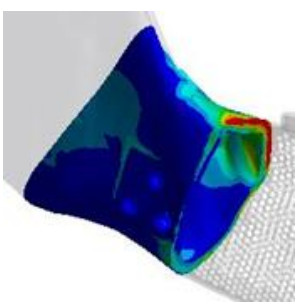

(e)

Figure 9. Distributions of von Mises strain in the bone of the models in RMOL mode (a) without pores, (b) with circular holes $2 \mathrm{~mm}$ in diameter, (c) with circular holes $1 \mathrm{~mm}$ in diameter, (d) with hexagonal holes $2 \mathrm{~mm}$ in diameter, and (e) with hexagonal holes $1 \mathrm{~mm}$ in diameter. 

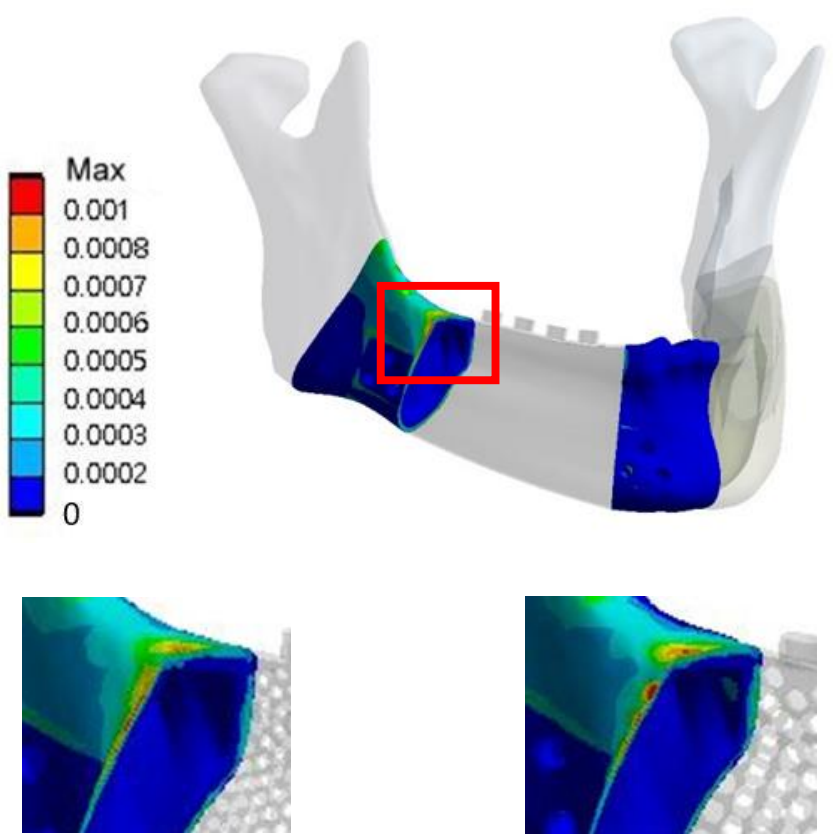

(c)

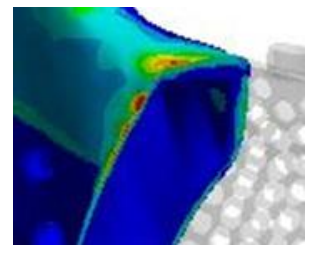

(d)

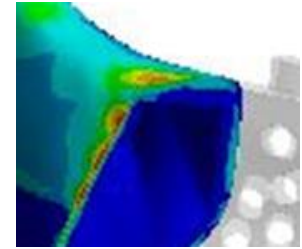

(a)

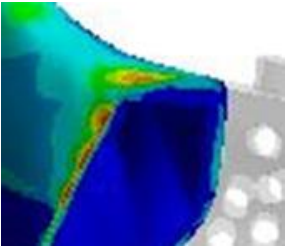

(b)

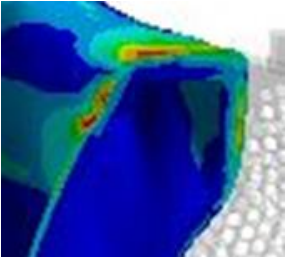

(e)

Figure 10. Distributions of von Mises strain in the bone of models the models in RGF mode (a) without pores, (b) with circular holes $2 \mathrm{~mm}$ in diameter, (c) with circular holes $1 \mathrm{~mm}$ in diameter, (d) with hexagonal holes $2 \mathrm{~mm}$ in diameter, and (e) with hexagonal holes $1 \mathrm{~mm}$ in diameter.

\section{Discussion}

The results of the in vitro experiments demonstrate the influence of the porous design on the implant and on the surrounding bone. The minimum principal strain of the control sample at position A was relatively small. Regarding the strain values of the bone around the implant (positions B and C), compared with the control sample, the experimental sample ( $1 \mathrm{~mm}$ circular holes) had a larger maximum principal strain and a smaller minimum principal strain. Overall, the compressive strain of the control sample was smaller, but more compressive strain was transmitted to the surrounding bone, resulting in higher compressive strain in that area. The opposite trend was detected in the strain results of the experimental sample ( $1 \mathrm{~mm}$ circular holes); the compressive strain of the implant body was lower, whereas the compressive strain of the surrounding bone was higher. However, the maximum principal strain (i.e., tensile strain) in the bone surrounding the experimental sample (1 mm circular holes) was higher than that in the bone surrounding the control sample.

The porous samples had higher stress values in position A than the nonporous implants. However, the porous design made the stress distribution of the implant relatively uniform. Moiduddin et al. (2017) [23] evaluated the biomechanical performance of a selfdesigned bone plate and a porous implant for correcting mandibular defects. They reported that the porous design uniformized the stress distribution of the implant, preventing the concentration of stress in a specific area of the implant body.

In the present study, the stress values of the implants with hexagonal holes were higher than those of implants with round holes. A possible reason is that stress can accumulate in the angles of the hexagonal holes. However, under both the RMOL and RGF modes, the stress values of the five implant designs did not exceed the yield strength of Ti6Al4V (800 MPa) [23]. In other words, regardless of whether the implants were porous or nonporous, they were not at immediate risk of breakage.

The present results indicate that the porous design exerted no absolute influence on the strain value of the bone surrounding the implants. The strain values of the bone 
surrounding the control sample and the sample with $1 \mathrm{~mm}$ circular holes were comparable. However, if implants with hexagonal holes were used, the strain of the surrounding bone was higher. Furthermore, the smaller the size of the hole, the higher the strain in the bone around the implant. Frost's mechanostat theory of bone [24,25] addresses the following four ranges of bone remodeling. (1) Disuse: when bone deformation is less than approximately $800 \mu \varepsilon$, bone resorption occurs, reducing bone quality and bone strength. (2) Adapted state: bone deformation is between approximately $800 \mu \varepsilon$ and approximately $1500 \mu \varepsilon$. Bone mass and bone strength remain constant, and bone absorption is equal to bone formation. (3) Overload: after bone deformation exceeds approximately $1500 \mu \varepsilon$, bone growth increases bone quality and bone strength. (4) Pathologic fracture: when the bone deformation exceeds approximately $15,000 \mu \varepsilon$, the elasticity of bone deformation exceeds the maximum allowable value, resulting in fracture [26]. According to the present results, regardless of whether the occlusal mode was RMOL or RGF, the strain in the surrounding bone did not exceed 15,000 $\mu \varepsilon$ in any model, meaning that no risk of bone fracture was immediate. However, compared with that in RGF mode, bone strain in RMOL mode was in the overload stage (between 2648 and $2813 \mu \varepsilon$ ), potentially promoting bone growth in the surrounding bone contacted by the implant. In RGF mode, the strain in the surrounding bone strain was between 1161 and $1493 \mu \varepsilon$ (adapted state), and the condition of the bone surrounding the implant could be maintained.

This study has some limitations. In the metal mandibular implant model, bone grafts were not placed in the hollow of the implant. The present analysis mainly simulated the biomechanical performance of the implants in the worst-case scenario, and the characteristics of bone materials were simplified to be homogeneous and isotropic, differing from real bone conditions. Furthermore, both the bone-screw interface and the bone plate-screw interface were bonded. This may not be the case in clinical contexts. Finally, animal experiments or preclinical studies are warranted to evaluate the feasibility of the implant models before their clinical application.

\section{Conclusions}

The conclusions are as follows. First, the porous implants had higher stress than the nonporous implants, but the value did not exceed the yield strength of Ti6Al4V (800 MPa), indicating that the porous implants were not at immediate risk of breakage. Second, the shape and size of the pores affected the stress value of the implant; specifically, implants with hexagonal holes had higher stress values than implants with circular holes. Finally, whether the implant was porous or nonporous, the strain in the surrounding bone was not consistent under differing occlusal conditions. Moreover, RMOL mode produced higher strain in the surrounding bone than RGF mode. According to Frost's mechanostat theory of bone, this higher strain may promote improvements in bone quality and bone strength.

Author Contributions: Conceptualization, Y.-W.S. and L.-J.F.; Data curation, Y.-S.T.; Formal analysis, Y.-S.T.; Funding acquisition, H.-L.H.; Investigation, Y.-S.T. and H.-L.H.; Methodology, J.-T.H., M.Y.S. and H.-L.H.; Resources, Y.-W.S., J.-T.H., M.-Y.S. and L.-J.F.; Software, L.-J.F.; Supervision, H.L.H.; Validation, Y.-S.T. and H.-L.H.; Writing—original draft, Y.-S.T. and H.-L.H.; Writing-review and editing, Y.-W.S. and H.-L.H. All authors have read and agreed to the published version of the manuscript.

Funding: This research was supported by Ministry of Science and Technology (Most 109-2221-E-039002-MY2) and China Medical University (CMU110-MF-103) in Taiwan.

Institutional Review Board Statement: The study was conducted in accordance with the Declaration of Helsinki, and approved by the Institutional Review Board of China Medical University Hospital (protocol no. CMUH108-REC3-174 in 22 January 2020).

Informed Consent Statement: Patient consent was waived because this study was retrospective. 
Data Availability Statement: The data that support the findings of this study are available from the corresponding author upon reasonable request.

Conflicts of Interest: The authors declare no conflict of interest.

\section{References}

1. Seikaly, H.; Chau, J.; Li, F.; Driscoll, B.; Seikaly, D.; Calhoun, J.; Calhoun, K.H. Bone that best matches the properties of the mandible. J. Otolaryngol. 2003, 32, 262-265. [CrossRef] [PubMed]

2. Bak, M.; Jacobson, A.S.; Buchbinder, D.; Urken, M.L. Contemporary reconstruction of the mandible. Oral Oncol. 2010, 46, 71-76. [CrossRef] [PubMed]

3. Foster, R.D.; Anthony, J.P.; Sharma, A.; Pogrel, M.A. Vascularized bone flaps versus nonvascularized bone grafts for mandibular reconstruction: An outcome analysis of primary bony union and endosseous implant success. Head Neck J. Sci. Spec. Head Neck 1999, 21, 66-71. [CrossRef]

4. Batstone, M. Reconstruction of major defects of the jaws. Aust. Dent. J. 2018, 63, S108-S113. [CrossRef]

5. Likhterov, I.; Roche, A.M.; Urken, M.L. Contemporary osseous reconstruction of the mandible and the maxilla. Oral Maxillofac. Surg. Clin. 2019, 31, 101-116. [CrossRef] [PubMed]

6. Sinjari, B.; D'Addazio, G.; De Tullio, I.; Traini, T.; Caputi, S. Peri-Implant Bone Resorption during Healing Abutment Placement: The Effect of a 0.20 Chlorhexidine Gel vs. Placebo-A Randomized Double Blind Controlled Human Study. BioMed Res. Int. 2018, 2018, 5326340. [CrossRef]

7. D’Ercole, S.; D’Addazio, G.; Di Lodovico, S.; Traini, T.; Di Giulio, M.; Sinjari, B. Porphyromonas Gingivalis load is balanced by $0.20 \%$ chlorhexidine gel. A randomized, double-blind, controlled, microbiological and immunohistochemical human study. J. Clin. Med. 2020, 9, 284. [CrossRef]

8. Sinibaldi, R.; Conti, A.; Sinjari, B.; Spadone, S.; Pecci, R.; Palombo, M.; Komlev, V.; Ortore, M.; Tromba, G.; Capuani, S. Multimodal3D imaging based on $\mu \mathrm{MRI}$ and $\mu \mathrm{CT}$ techniques bridges the gap with histology in visualization of the bone regeneration process. J. Tissue Eng. Regen. Med. 2018, 12, 750-761. [CrossRef] [PubMed]

9. Vaish, A.; Vaish, R. 3D printing and its applications in Orthopedics. J. Clin. Orthop. Trauma 2018, 9, S74-S75. [CrossRef]

10. Frizziero, L.; Santi, G.M.; Liverani, A.; Giuseppetti, V.; Trisolino, G.; Maredi, E.; Stilli, S. Paediatric orthopaedic surgery with 3D printing: Improvements and cost reduction. Symmetry 2019, 11, 1317. [CrossRef]

11. Eshkalak, S.K.; Ghomi, E.R.; Dai, Y.; Choudhury, D.; Ramakrishna, S. The role of three-dimensional printing in healthcare and medicine. Mater. Des. 2020, 108940. [CrossRef]

12. Eltorai, A.E.; Nguyen, E.; Daniels, A.H. Three-dimensional printing in orthopedic surgery. Orthopedics 2015, $38,684-687$. [CrossRef] [PubMed]

13. Marinescu, R.; Popescu, D.; Laptoiu, D. A Review on 3D-Printed Templates for Precontouring Fixation Plates in Orthopedic Surgery. J. Clin. Med. 2020, 9, 2908. [CrossRef]

14. Nadagouda, M.N.; Rastogi, V.; Ginn, M. A review on 3D printing techniques for medical applications. Curr. Opin. Chem. Eng. 2020, 28, 152-157. [CrossRef]

15. Cheng, L.; Shoma Suresh, K.; He, H.; Rajput, R.S.; Feng, Q.; Ramesh, S.; Wang, Y.; Krishnan, S.; Ostrovidov, S.; Camci-Unal, G. 3D printing of micro-and nanoscale bone substitutes: A review on technical and translational perspectives. Int. J. Nanomed. 2021, 16, 4289-4319. [CrossRef] [PubMed]

16. Memon, A.R.; Wang, E.; Hu, J.; Egger, J.; Chen, X. A review on computer-aided design and manufacturing of patient-specific maxillofacial implants. Expert Rev. Med. Devices 2020, 17, 345-356. [CrossRef] [PubMed]

17. Du, R.; Su, Y.-X.; Yan, Y.; Choi, W.S.; Yang, W.-F.; Zhang, C.; Chen, X.; Curtin, J.P.; Ouyang, J.; Zhang, B. A Systematic Approach for Making 3D-Printed Patient-Specific Implants for Craniomaxillofacial Reconstruction. Engineering 2020, 6, 1291-1301. [CrossRef]

18. Bianchi, G.; Frisoni, T.; Spazzoli, B.; Lucchese, A.; Donati, D. Computer Assisted Surgery and 3D Printing in Orthopaedic Oncology: A Lesson Learned by Cranio-Maxillo-Facial Surgery. Appl. Sci. 2021, 11, 8584. [CrossRef]

19. Huang, S.-N.; Shie, M.-Y.; Shen, Y.-W.; Hsu, J.-T.; Huang, H.-L.; Fuh, L.-J. Biomechanical Assessment of Design Parameters on a Self-Developed 3D-Printed Titanium-Alloy Reconstruction/Prosthetic Implant for Mandibular Segmental Osteotomy Defect. Metals 2019, 9, 597. [CrossRef]

20. Yao, C.; Chen, D.; Zheng, Z.; Wang, Q.; Fu, K. Research on porous titanium implants and its animal experiments. Rapid Prototyp. J. 2020, 27, 13-23. [CrossRef]

21. Korioth, T.W.; Hannam, A.G. Mandibular forces during simulated tooth clenching. J. Orofac. Pain 1994, 8, 178-189. [PubMed]

22. Huang, H.-L.; Su, K.-C.; Fuh, L.-J.; Chen, M.Y.; Wu, J.; Tsai, M.-T.; Hsu, J.-T. Biomechanical analysis of a temporomandibular joint condylar prosthesis during various clenching tasks. J. Cranio-Maxillofac. Surg. 2015, 43, 1194-1201. [CrossRef] [PubMed]

23. Moiduddin, K. Implementation of computer-assisted design, analysis, and additive manufactured customized mandibular implants. J. Med. Biol. Eng. 2018, 38, 744-756. [CrossRef]

24. Frost, H.M. Bone "mass" and the "mechanostat": A proposal. Anat. Rec. 1987, 219, 1-9. [CrossRef] [PubMed]

25. Hubbell, Z.R. Mechanostat. Int. Encycl. Biol. Anthropol. 2018, 1-2.

26. Biewener, A.A. Safety factors in bone strength. Calcif. Tissue Int. 1993, 53, S68-S74. [CrossRef] 